\title{
Characteristics of orbital wall fractures in preschool and school-aged children
}

\author{
Dong Jin Yang, Youn-Jung Kim, Dong-Woo Seo, Hyung-Joo Lee, \\ In-June Park, Chang Hwan Sohn, Jung Min Ryoo, Jong Seung Lee, \\ Won Young Kim, Kyoung Soo Lim
}

Department of Emergency Medicine, Asan Medical Center, University of Ulsan College of Medicine, Seoul, Korea

Objective This study aimed to evaluate the injury patterns in pediatric patients with an orbital wall fracture (OWF) and to identify the differences in injury patterns between preschool and schoolaged patients with OWF who presented to the emergency department.

Methods We performed a retrospective observational study in the emergency department of a tertiary hospital between January 2004 and March 2014. A total of 177 pediatric patients $(<18$ years) with OWF who underwent facial bone computed tomography scans with specific discharge codes were included. Patients were categorized into preschool ( $\leq 7$ years) and schoolaged ( $>7$ years) pediatric groups.

Results The inferior wall was the most common fracture site in both the preschool and schoolaged pediatric groups (50.0\% vs. $64.4 \%, \mathrm{P}=0.15)$. The male-to-female ratio and the mechanism of injury showed significant differences between the two age groups. Violence was the most common mechanism of injury in the school-aged pediatric group (49.3\%), whereas falls from a height caused OWF in approximately half of the patients in the preschool pediatric group (42.9\%). Concomitant injuries and facial fractures had a tendency to occur more frequently in the school-aged pediatric group.

Conclusion Significant differences according to the sex and mechanisms of injury were identified in preschool and school-aged pediatric patients with OWF.

Keywords Orbital fractures; Pediatric; Facial injuries; Computed tomography; Emergency medical services

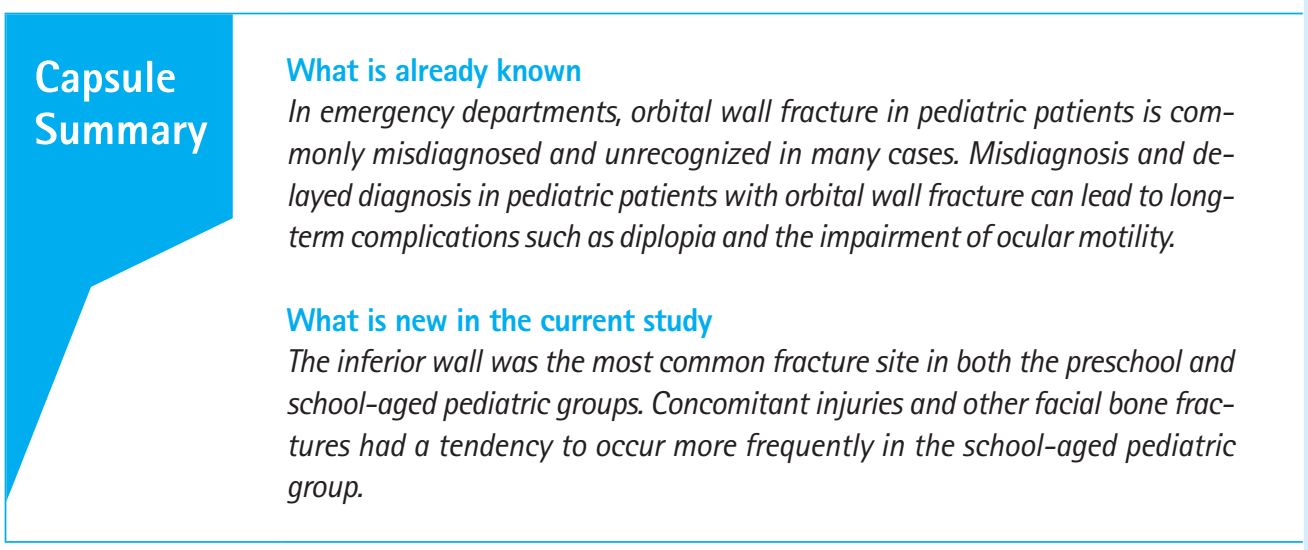

Received: 2 November 2016 Revised: 28 December 2016 Accepted: 1 February 2017

Correspondence to: Dong-Woo Seo Department of Emergency Medicine, Asan Medical Center, University of Ulsan College of Medicine, 88 Olympicro 43-gil, Songpa-gu, Seoul 05505, Korea

E-mail: leiseo@gmail.com

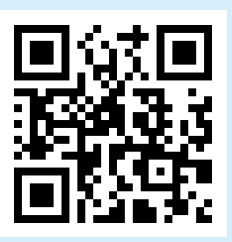

How to cite this article:

Yang DJ, Kim YJ, Seo DW, Lee HJ, Park IJ, Sohn CH, Ryoo JM, Lee JS, Kim WY, Lim KS. Characteristics of orbital wall fractures in preschool and school-aged children. Clin Exp Emerg Med 2017;4(1):32-37.

This is an Open Access article distributed under the terms of the Creative Commons Attribution Non-Commercial License (http:// creativecommons.org/licenses/by-nc/4.0/). 


\section{INTRODUCTION}

Injured patients usually visit the emergency department (ED) because of its timely management of cases and 24-hour accessibility. In patients with blunt facial trauma, emergency physicians perform a thorough ophthalmic examination to evaluate for the possibility of orbital wall fractures (OWFs).

OWF is rare in pediatric trauma patients, and achieving the correct diagnosis can be challenging. In EDs, OWF in pediatric patients is commonly misdiagnosed and unrecognized in as many as 30\% of cases. ${ }^{1}$ Recent studies have suggested that when surgery is indicated in pediatric patients with OWF, early surgical intervention results in better outcomes with fewer complications, which is not necessarily the case in adult patients. ${ }^{2-4}$

Misdiagnosis and delayed diagnosis in pediatric patients with OWF can contribute to long-term complications such as permanent diplopia and the restriction of ocular motility. ${ }^{3,4}$ Thus, thorough and immediate evaluation of OWF in EDs, followed by the appropriate clinical management, are important for pediatric patients. ${ }^{5-7}$ However, there is little evidence regarding the injury pattern of OWF in pediatric patients to aid ED physicians in diagnosis. The objectives of this study were (1) to evaluate the injury patterns and concomitant injuries in pediatric patients with OWF and (2) to identify the differences between injury patterns in preschool and school-aged patients with OWF who presented to the ED.

\section{METHODS}

\section{Study design and setting}

We conducted a retrospective case-control study at the ED of our hospital between January 1, 2004 and March 31, 2014. All consecutive patients with OWF who presented at the ED were retrospectively identified using discharge codes according to the International Classification of Diseases 10th revision (ICD-10) from the de-identified clinical data warehouse of our institute. ${ }^{8}$ The electronic medical records of eligible patients were reviewed for evaluation. Our hospital is a university-affiliated, tertiary referral center located in an urban area, which treats approximately 110,000 patients per year in the ED. The institutional review board of our hospital approved the review of patient data and waived the requirement for informed consent because of the retrospective nature of the study.

\section{Selection of participants}

In this study, we included 177 pediatric patients (aged $<18$ years) who underwent facial bone computed tomography (CT) scans and who were discharged with specific ICD-10 codes. Patients were excluded if they were referred from another hospital after the diagnosis of OWF due to their incomplete medical records or no formal interpretive reports of CT scans. All orbital fractures were confirmed using facial bone CT scans, which included fractures of one or more walls of the orbit (frontal bone, sphenoid bone, zygoma, maxillary bone, and ethmoid bone), the orbital rim, or both. ${ }^{9}$ We hypothesized that attending a school affected the mechanism of injury. Therefore, patients who were 7 years or younger were included in the preschool pediatric group, and patients older than 7 years were included in the school-aged pediatric group, based on the age at the time of injury. Patients in the school-aged pediatric group were further categorized into elementary ( 7 to 12 years), middle (13 to 15 years), and high (16 to 17 years) school-aged pediatric groups.

\section{Data collection}

Data regarding age, sex, injury mechanism, site of orbital wall fracture, and concomitant facial bone fractures were collected from formal interpretive reports of CT scans prepared by radiology specialists. The common signs and symptoms of OWF were also noted, including diplopia, ecchymosis, emphysema, enophthalmus, and periorbital swelling. In our hospital, an emergency physician initially collected patient history and performed physical examinations, including ophthalmic examinations. We categorized the mechanisms of injury into five groups: falls from heights, ground-level falls, motor vehicle accidents, violence, and other causes (penetrating and other blunt trauma). After patients were diagnosed with an orbital fracture on CT examination, an ophthalmologist performed a full ophthalmic examination. An emergency physician and ophthalmologist prepared their respective medical records.

\section{Statistical analysis}

Data were expressed as median with interquartile range for continuous variables and as numbers and percentages for categorical variables. The Mann-Whitney U-test was used to compare continuous variables, and the Pearson's chi-square test or Fisher's exact test was applied for categorical variables. For all analyses, a two-sided P-value of $<0.05$ was considered to indicate a statistically significant difference. Statistical analyses were performed using IBM SPSS ver. 20 (IBM Corp., Armonk, NY, USA).

\section{RESULTS}

Between January 1, 2004 and March 31, 2014, 177 pediatric patients (aged $<18$ years) were included in our study. They were 
Table 1. Demographic and clinical characteristics of pediatric patients with orbital wall fracture in preschool and school-aged groups

\begin{tabular}{|c|c|c|c|c|c|c|c|}
\hline Variable & $\begin{array}{c}\text { Total } \\
(n=177)\end{array}$ & $\begin{array}{c}\text { Preschool pediatric } \\
\text { group } \\
(n=25)\end{array}$ & $\begin{array}{l}\text { School-aged } \\
\text { pediatric group } \\
\quad(n=152)\end{array}$ & P-value & $\begin{array}{l}\text { Elementary school- } \\
\text { aged pediatric group } \\
\qquad(n=44)\end{array}$ & $\begin{array}{l}\text { Middle school-aged } \\
\text { pediatric group } \\
(n=47)\end{array}$ & $\begin{array}{l}\text { High school-aged } \\
\text { pediatric group } \\
\qquad(n=61)\end{array}$ \\
\hline Age (yr) & $13.0(10.5-16.0)$ & $2.0(1.0-6.0)$ & $14.0(12.0-17.0)$ & $<0.001$ & $11.0(9.0-12.0)$ & $13.0(13.0-14.0)$ & $17.0(16.0-17.0)$ \\
\hline Sex, male & $155(87.6)$ & $13(52.0)$ & $142(93.4)$ & $<0.001$ & $38(86.4)$ & 45 (95.7) & 59 (96.7) \\
\hline \multicolumn{8}{|l|}{ Mechanism of injury } \\
\hline Violence & $76(42.9)$ & $1(4.0)$ & 75 (49.3) & $<0.001$ & $15(34.1)$ & $28(59.6)$ & $32(52.5)$ \\
\hline Traffic accident & $30(16.9)$ & $5(20.0)$ & $25(16.4)$ & 0.77 & $4(9.1)$ & $3(6.4)$ & 18 (29.5) \\
\hline Ground level falls & $21(11.9)$ & $3(12.0)$ & 18 (11.8) & 0.99 & $9(20.5)$ & $5(10.6)$ & $4(6.6)$ \\
\hline Falls from heights & $14(7.9)$ & $12(48.0)$ & $2(1.3)$ & $<0.001$ & $0(0)$ & $1(2.1)$ & $1(1.6)$ \\
\hline Other causes ${ }^{\mathrm{a})}$ & $36(20.3)$ & 4 (16.0) & $32(21.1)$ & 0.56 & $16(36.4)$ & $10(21.3)$ & $6(9.8)$ \\
\hline \multicolumn{8}{|l|}{ Signs and symptoms } \\
\hline Periorbital swelling & 157 (88.7) & $25(100.0)$ & $132(86.8)$ & 0.08 & $35(79.5)$ & $40(85.1)$ & $57(93.4)$ \\
\hline Ecchymosis & 94 (53.1) & $18(72.0)$ & $76(50.0)$ & 0.04 & $20(45.5)$ & $25(53.2)$ & $31(50.8)$ \\
\hline Emphysema & $32(18.1)$ & $3(12.0)$ & $29(19.1)$ & 0.58 & $9(20.5)$ & $5(10.6)$ & $15(24.6)$ \\
\hline Diplopia & $19(10.7)$ & $1(4.0)$ & 18 (11.8) & 0.48 & $6(13.6)$ & $8(17.0)$ & $4(6.6)$ \\
\hline Enophthalmos & $7(4.0)$ & $1(4.0)$ & $6(3.9)$ & 0.99 & $4(9.1)$ & $1(2.1)$ & $1(1.6)$ \\
\hline
\end{tabular}

Values are presented as median (interquartile range) or number (\%).

a) Of 36 patients, orbital wall fracture was caused by sports-related trauma $(n=13)$, an object collision $(n=11)$, a collision against other person $(n=10)$, and unknown mechanism $(n=2)$.

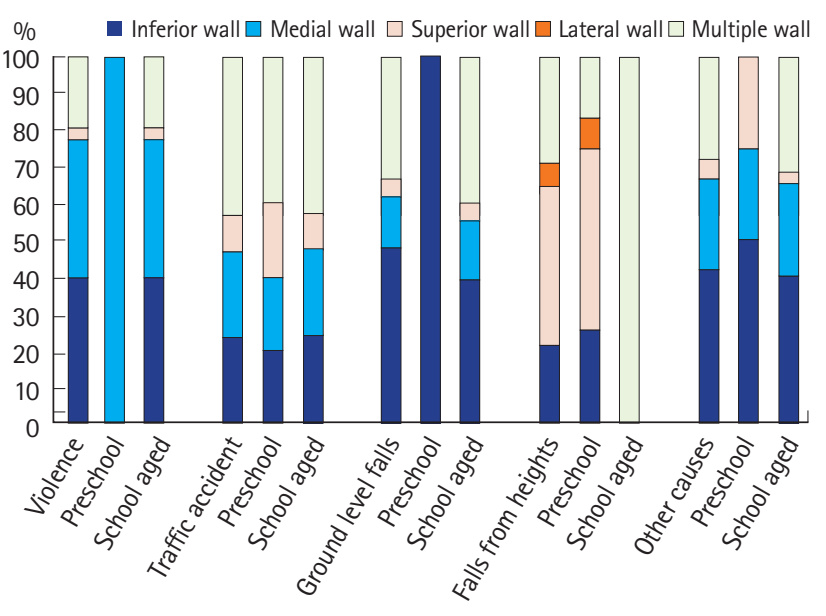

Fig. 1. The site of orbital wall fracture according to mechanism of injury. Mechanism of injury including violence, traffic accident, ground level falls, and falls from heights were listed in order of frequency.

categorized into preschool pediatric $(n=25)$ and school-aged pediatric groups $(n=152)$ based on age (below or above 7 years) (Table 1). The male-to-female ratio was approximately 1:1 in the preschool pediatric group (male, 52.0\%), whereas an overwhelming majority of the patients in the school-aged pediatric group were male $(93.4 \%, \mathrm{P}<0.001)$.

There were differences in the mechanisms of injury between the two groups. Violence was the most common mechanism of injury in the school-aged pediatric group (49.3\%) and it tended to occur more commonly in middle and high school-aged pediatric groups. In contrast, violence was the least common mechanism of injury in the preschool pediatric group $(4.0 \%, \mathrm{P}<0.001)$. Approximately half of the OWFs in the preschool pediatric group
(48.0\%) resulted from falls from a height, whereas falls from a height caused OWFs in only two of 149 patients (1.3\%) in the school-aged pediatric group $(\mathrm{P}<0.001)$. The site of OWF according to the mechanism of injury is presented in Fig. 1. Multiple OWFs were observed in patients injured in traffic accidents (total, 43.3\%; preschool pediatric group, 40.0\%; school-aged pediatric group, 44.0\%) and falls from height (total, 28.6\%; preschool pediatric group, 16.7\%; school-aged pediatric group, 100.0\%). No significant differences in regard to clinical signs and symptoms were noted between the two groups; the most common sign was periorbital swelling ( $100 \%$ vs. $86.8 \%, P=0.08)$, followed by ecchymosis $(72.0 \%$ vs. $50.0 \%, P=0.04)$, and emphysema ( $12.0 \%$ vs. $19.1 \%, P=0.58)$.

Periorbital swelling was the most common sign in all OWF types (inferior OWF, 90.0\%; medial OWF, 88.8\%; superior OWF, 95.7\%; lateral OWF, 100.0\%), followed by ecchymosis (inferior OWF, 55.5\%; medial OWF, 48.3\%; superior OWF, 56.5\%; lateral OWF, 75.0\%), and emphysema (inferior OWF, 20.9\%; medial OWF, 22.5\%; superior OWF, 17.4\%; lateral OWF, 33.3\%). Diplopia (inferior $\mathrm{OWF}, 14.5 \%$; medial $\mathrm{OWF}, 6.7 \%$; superior $\mathrm{OWF}$, 0\%; lateral OWF, 8.3\%) and enophthalmus (inferior OWF, 5.5\%; medial OWF, 4.5\%; superior $O W F, 4.3 \%$; lateral $O W F, 8.3 \%$ ) were uncommon signs in all OWF types.

Based on the facial bone CT reports, the distribution of OWF showed a different pattern in the preschool versus school-aged pediatric groups (Table 2). The inferior wall was the most common fracture site for both age groups ( $44.0 \%$ vs. $65.1 \%, P=0.04$ ). However, the second most common fracture site in the preschool pediatric group was the superior wall $(36.0 \%$ vs. $9.2 \%, P=0.001)$, 
Table 2. Radiologic findings for pediatric patients with orbital wall fracture in the preschool and school-aged groups

\begin{tabular}{|c|c|c|c|c|}
\hline Variable & $\begin{array}{c}\text { Total } \\
(n=177)\end{array}$ & $\begin{array}{l}\text { Preschool pediatric group } \\
\qquad(n=25)\end{array}$ & $\begin{array}{l}\text { School-aged pediatric group } \\
\qquad(n=152)\end{array}$ & P-value \\
\hline \multicolumn{5}{|l|}{ Types of orbital wall fractures } \\
\hline Inferior wall & $110(62.1)$ & $11(44.0)$ & $99(65.1)$ & 0.04 \\
\hline Medial wall & 89 (50.3) & 7 (28.0) & $82(53.9)$ & 0.02 \\
\hline Superior wall & $23(13.0)$ & $9(36.0)$ & $14(9.2)$ & 0.001 \\
\hline Lateral wall & $12(6.8)$ & $2(8.0)$ & $10(6.6)$ & 0.68 \\
\hline Multiple orbital wall fractures & $49(27.7)$ & $4(16.0)$ & $45(29.6)$ & 0.16 \\
\hline \multicolumn{5}{|l|}{ Concomitant injuries } \\
\hline Fat herniation & $50(28.2)$ & $3(12.0)$ & 47 (30.9) & 0.05 \\
\hline EOM hernia & $13(7.3)$ & $2(8.0)$ & $11(7.2)$ & 0.99 \\
\hline EOM entrapment & $10(5.6)$ & $2(8.0)$ & $8(5.3)$ & 0.64 \\
\hline Orbital hematoma & $2(1.1)$ & $0(0)$ & $2(1.3)$ & 0.99 \\
\hline Hemosinus & $78(44.1)$ & $6(24.0)$ & $72(47.4)$ & 0.03 \\
\hline Concomitant facial bone fracture & $57(32.2)$ & $6(24.0)$ & $51(33.6)$ & 0.34 \\
\hline Maxilla fracture & $29(16.4)$ & $2(8.0)$ & $27(17.8)$ & 0.38 \\
\hline Nasal bone fracture & $28(15.8)$ & $0(0)$ & $28(18.4)$ & 0.02 \\
\hline Frontal bone fracture & $18(10.2)$ & $3(12.0)$ & $15(9.9)$ & 0.72 \\
\hline Zygoma fracture & $13(7.3)$ & $1(4.0)$ & $12(7.9)$ & 0.70 \\
\hline Mandible fracture & $2(1.1)$ & $0(0)$ & $2(1.3)$ & 0.99 \\
\hline Multiple facial bone fractures & $23(13.0)$ & $0(0)$ & $23(15.1)$ & 0.05 \\
\hline
\end{tabular}

Values are presented as number (\%).

EOM, extraocular muscle.

whereas it was the medial wall for the school-aged pediatric group (28.0\% vs. $53.9 \%, P=0.02)$. The school-aged pediatric patients seemed to more frequently sustain multiple OWFs compared with that sustained by preschool pediatric patients; however, this finding was without statistical significance (16.0\% vs. $29.6 \%, P=0.16)$.

Concomitant injuries and facial fractures seemed to occur more frequently in the school-aged pediatric group; however, no statistically significant difference was noted. Hemosinus was the most common concomitant injury in preschool and school-aged pediatric patients $(44.1 \%)$, followed by fat herniation (28.2\%), extraocular muscle herniation (7.3\%), and extraocular muscle entrapment (5.6\%). Concomitant facial fractures were less frequently observed in preschool pediatric patients than in schoolaged pediatric patients $(24.0 \%$ vs. $33.6 \%, P=0.34)$. This tendency was noted for all facial bone fractures except frontal bone fracture $(12.0 \%$ vs. $9.9 \%, P=0.72)$. None of the patients in the preschool pediatric group had multiple facial bone fractures $(0 \%$ vs. $15.1 \%, P=0.05)$.

\section{DISCUSSION}

In this study, we evaluated the injury patterns and concomitant injuries in pediatric patients with OWF and identified differences according to age at the time of injury (preschool and school-aged pediatric groups). The sex ratio, mechanism of injury, and the in- cidence of OWF site were different in the preschool vs. schoolaged pediatric groups. The inferior wall was the most common fracture site in pediatric patients, and concomitant as well as multiple facial bone fractures were less likely to occur in preschool pediatric patients. These findings imply that anatomic changes as well as activity changes consistent with childhood development contributed to the differences in injury pattern and the magnitude of concomitant injuries.

Pediatric trauma patients have different anatomic features and demonstrate different physiologic responses to injury. The management of these patients involves more complex decision-making because they are still in the process of development. In our study, the male-to-female ratio varied significantly between the preschool and school-aged pediatric groups (52.0\% vs. $93.4 \%$ male, $\mathrm{P}<0.001)$. The predominance of male patients with facial trauma has been observed in other studies and may be attributed to the differences in physical activities between boys and girls..$^{10,11}$ Similarly, the mechanism of injury differed between the preschool and school-aged pediatric groups. Falls from a height caused $48.0 \%$ of OWFs in the preschool pediatric group, in contrast to $1.3 \%$ of OWFs in the school-aged pediatric group $(P<0.001)$. Furthermore, only one patient (4.0\%) in the preschool pediatric group experienced OWF as a result of violence, as compared with half of the patients in the school-aged pediatric group (4.0\% vs. $49.3 \%, \mathrm{P}<0.001)$. This contrast might be attributed to the development of coordination function in older children. A difference in 
physical activities by age might also be responsible, with schoolaged children engaging in riskier (and more violent) behavior.

The age-related differences in mechanisms of injury might have contributed to the differences between OWF injury patterns and concomitant injuries in preschool versus school-aged patients. Interestingly, there was no statistically significant difference in the frequency of concomitant facial bone fractures between the preschool and school-aged pediatric groups (24.0\% vs. $33.6 \%, P=0.34$ ), but the frequency of multiple facial bone fractures was higher in the school-aged pediatric group (15.1\% vs. $0 \%, \mathrm{P}=0.05)$.

Despite the lack of significance, concomitant injuries, including fractures of the sinus, maxilla, nasal bone, and zygoma, did tend to occur more frequently in the school-aged pediatric group than in the preschool pediatric group. These differences might be attributed to anatomic changes. Many previous studies have suggested that after the age of 7 years, faces and sinuses become more vulnerable to blunt facial trauma., ${ }^{6,12,13}$ Zimmermann et al. ${ }^{14}$ revealed that the cranial-to-facial proportion is nearly $8: 1$ at birth, which makes younger children more vulnerable to skull fractures than to facial fractures. Hatef et al. ${ }^{15}$ also demonstrated that younger children had more stable facial skeletal structures as compared with those of adults. Similarly, Koltai et al. ${ }^{16}$ demonstrated that younger children had thicker sinus walls, greater bony elasticity, and more cheek fat pad, which protected them from facial injury.

This study had some limitations that should be acknowledged. First, this was a retrospective study and thus was subject to potential errors inherent to this type of study, such as selection bias. Second, the possibility of referral bias should be considered in our study, since it was based at a university-affiliated, tertiary referral center with both a pediatric ophthalmology referral center and a pediatric ED. Third, although all patients had routine ophthalmologic examinations, these were sometimes incomplete when the patients were severely injured. Additionally, in comparison with older children, the youngest patients were not cooperative during history-taking and ophthalmologic examination. History-taking was often performed with parents serving as a proxy instead, thereby introducing a potential error, especially in cases of child abuse. Fourth, the high school-aged group should ideally include patients aged 16 to 18 years; however, we included only the patients less than 18 years old. Fifth, we evaluated all injuries using CT scans, which can underestimate muscle and soft tissue injuries in the pediatric population. ${ }^{17}$ As a result, the underdiagnosis of concomitant injuries might have occurred in our patients, but this reflects the modality of choice in real clinical practice. Lastly, our study did not evaluate the outcomes in pediatric patients with
OWF; further studies are required.

In conclusion, we identified significant differences between preschool and school-aged pediatric patients with OWF in regard to sex ratio and mechanism of injury. The inferior wall was the most common site of fracture in both groups. School-aged pediatric patients tended to have concomitant injuries and more multiple facial bone fractures than preschool patients.

\section{CONFLICT OF INTEREST}

No potential conflict of interest relevant to this article was reported.

\section{REFERENCES}

1. Cobb A, Murthy R, Manisali M, Uddin J, Toma A. Oculovagal reflex in paediatric orbital floor fractures mimicking head injury. Emerg Med J 2009;26:351-3.

2. Egbert JE, May K, Kersten RC, Kulwin DR. Pediatric orbital floor fracture: direct extraocular muscle involvement. Ophthalmology 2000;107:1875-9.

3. Gerbino G, Roccia F, Bianchi FA, Zavattero E. Surgical management of orbital trapdoor fracture in a pediatric population. J Oral Maxillofac Surg 2010;68:1310-6.

4. Wang NC, Ma L, Wu SY, Yang FR, Tsai YJ. Orbital blow-out fractures in children: characterization and surgical outcome. Chang Gung Med J 2010;33:313-20.

5. Hink EM, Wei LA, Durairaj VD. Clinical features and treatment of pediatric orbit fractures. Ophthal Plast Reconstr Surg 2014; 30:124-31.

6. Baek SH, Lee EY. Clinical analysis of internal orbital fractures in children. Korean J Ophthalmol 2003;17:44-9.

7. Cope MR, Moos KF, Speculand B. Does diplopia persist after blow-out fractures of the orbital floor in children? $\mathrm{Br} J$ Oral Maxillofac Surg 1999;37:46-51.

8. Shin SY, Park YR, Shin Y, et al. A De-identification method for bilingual clinical texts of various note types. J Korean Med Sci 2015;30:7-15.

9. Manolidis S, Weeks BH, Kirby M, Scarlett M, Hollier L. Classification and surgical management of orbital fractures: experience with 111 orbital reconstructions. J Craniofac Surg 2002; 13:726-37.

10. Kotecha S, Scannell J, Monaghan A, Williams RW. A four year retrospective study of 1,062 patients presenting with maxillofacial emergencies at a specialist paediatric hospital. $\mathrm{Br} J$ Oral Maxillofac Surg 2008:46:293-6.

11. Al Shetawi AH, Lim CA, Singh YK, Portnof JE, Blumberg SM. 
Pediatric maxillofacial trauma: a review of 156 patients. J Oral Maxillofac Surg 2016;74:1420.e1-4.

12. Hatton MP, Watkins $L M$, Rubin PA. Orbital fractures in children. Ophthal Plast Reconstr Surg 2001;17:174-9.

13. Bansagi ZC, Meyer DR. Internal orbital fractures in the pediatric age group: characterization and management. Ophthalmology 2000;107:829-36.

14. Zimmermann CE, Troulis MJ, Kaban LB. Pediatric facial fractures: recent advances in prevention, diagnosis and management. Int J Oral Maxillofac Surg 2006;35:2-13.
15. Hatef DA, Cole PD, Hollier LH Jr. Contemporary management of pediatric facial trauma. Curr Opin Otolaryngol Head Neck Surg 2009;17:308-14.

16. Koltai PJ, Amjad I, Meyer D, Feustel PJ. Orbital fractures in children. Arch Otolaryngol Head Neck Surg 1995;121:1375-9.

17. Parbhu KC, Galler KE, Li C, Mawn LA. Underestimation of soft tissue entrapment by computed tomography in orbital floor fractures in the pediatric population. Ophthalmology 2008; 115:1620-5. 